\title{
Numerical Analysis of the Interaction between Shallow (Square, Circular and Strip) Foundations and Subsoil
}

\author{
L'uboš Hruštinec \\ Department of Geotechnics, Faculty of Civil Engineering, Slovak University of Technology in Bratislava, Bratislava 81368 , \\ Slovakia
}

\begin{abstract}
In this paper, the effects of the stiffness of circular, square and strip foundation structures and bonding effects were analyzed. Presented analysis was oriented on the influence of stiffness system "foundation — subsoil" and bonds (bi-directional bond and one-directional bond with and without friction). The results of numerical calculations have proved that the relative stiffness of system "foundation - subsoil" affect considerably the value and the distribution of contact stresses (vertical normal and shear stresses) in the foundation gap and value of the displacements (settlement, deflection and relative deformations) of foundation. From the numerical point of view, this problem was solved by deformation variant of the FEM (finite element method). The numerically obtained results were presented in the graphical and tabular forms. Obtained results were qualitative and quantitative compared with one another. From the calculation results it is obvious that relative stiffness of the system "foundation structure-subsoil" substantially affects distribution of contact stresses in the foundation subsoil and displacements (settlement, deflection and relative deformations, flexibility) of foundation. In the case of flexible foundations, the bond on the contact surfaces must be considered during the calculation. On the other hand, the effects of friction on the contact surface between the foundation and subsoil affect the distribution of contact stresses and deformations only to smaller extent.
\end{abstract}

Key words: Shallow foundations, contact stresses, displacements, stiffness of foundations, FEM modeling.

\section{Introduction}

In this study, the author deals with numerical analysis of the contact stresses and deformation (settlement), deflection and relative deformation under rigid and flexible shallow circular, square and strip foundations. Presented analysis was focused on the influence of stiffness system "foundation-subsoil" and bonds (bi-directional bond and one-directional bond with and without friction) on the values of:

(1) the vertical normal and shear contact stresses;

(2) the deformation (settlement), deflection and relative deformation (relative settlement, relative deflection and flexibility).

During the foundations design and assessment according to the limit states it is necessary to know the

Corresponding author: L'uboš Hruštinec, Ph.D., assistant professor, research fields: geotechnical engineering, soil mechanics, foundations, soil structure interaction, and finite element method modeling in geotechnics. E-mail: lubos.hrustinec@stuba.sk. intensity and distribution of contact stresses and their deformations in the foundation bottom. Generally, it is expected that the stress distribution and deformations depend on the relative stiffness of the foundation in contact with subsoil. The most significant factors affecting the relative stiffness of shallow (circular, square and strip) foundations are:

(1) geometrical shape, dimensions and deformation properties of the foundations;

(2) non-homogenity, anisotropy and deformation properties of the subsoil;

(3) bonds and friction on the contact area between foundation and subsoil;

(4) type, intensity and distribution of loading.

These factors significantly affect the selection of the input data for the numerical calculations and pre-determine complexity of the boundary conditions of the analyzed problem.

For a reliable building structures design, interaction between the foundation structure and the subsoil must 
be considered. Many authors have been dealing with this topic. Interaction of structure and subsoil was analyzed in detail by Bolteus [1]. Theoretical analyses of the problem were presented in Refs. [2-7]. Some results of measurements made on the models of interaction between the structure and subsoil were published in Refs. [8, 9]. At the present time, the mathematical modeling using the FEM (finite element method) has been mostly used for solution of problems in interaction of building structure and subsoil. Theoretical assumptions as well as practical applications of FEM in the engineering practice were mentioned by Zienkiewicz and Taylor [10, 11]. Numerical modeling (FEM) of interaction between building (foundation) structure and the subsoil was dealt with by authors in Refs. [12-17]. Bose and Das [18] employed the FEM in their analysis of stress and deformation below the rigid foundation. Some calculations of settlement of sheet structures on the sand subsoil were presented in Refs. [19-22]. Effects of foundation stiffness upon the distribution of contact stresses were analyzed in Refs. [23-24]. Some analyses of the friction between the foundation and subsoil were presented by Santos and Quera [25]. Complex numerical analyses of the interaction of shallow (square, circular and strip) foundations with subsoil, presented in this paper, were published in Ref. [26]. In this work, the effects of the square, circular and strip foundations stiffness and bonds (bi-directional and one-directional with and without friction) on the contact surface of foundation and the distribution and value of vertical normal stresses, shear stresses and deformations were analyzed in more detail.

\section{Boundary Conditions of Solved Problem}

The problem of the interaction between shallow foundations and subsoil was solved by mathematical modeling using FEM. For the presented analysis, computer program ANSYS $^{\circledR}$ [27] was used. It was important to observe the physical principles. The contact task was solved as a $3 \mathrm{D}$ problem according to assumptions of the linear elastic half-space theory.

From the viewpoint of the effects of bonds, the contact surface between the foundation and subsoil was modeled for three following cases:

(1) bi-directional bond (transmission of pressure and tensile forces and shear forces at the solid contact between foundation and subsoil);

(2) one-directional bond with friction (transmission only due to pressure forces and shear forces depending on the value of the angle of internal friction $\left.\varphi=35^{\circ}\right)$;

(3) one-directional bond without friction (transmission only due to pressure forces, and shear forces depending on the value of the angle of internal friction $\varphi=0^{\circ}$ ).

The disadvantage of the bi-directional bond model is the transmission of the tension forces between square foundation and subsoil. Model with one-directional bond represents behavior of real foundation more precisely.

The geometrical shape is one of the most general factors affecting the relative stiffness of the system "foundation-subsoil". Geometrical parameters and stiffness of analyzed square, circular and strip foundations models are given in Table 1. The relative stiffness " $k$ " of foundation was defined according to the Eq. (1) [28]:

$$
k=\frac{E_{f}}{E_{\text {def }}}\left(\frac{t}{B}\right)^{3} \text { or } k=\frac{E_{f}}{E_{d e f}}\left(\frac{t}{L}\right)^{3}
$$

where,

$E_{f}$ is modulus of elasticity of foundation;

$E_{\text {def }}$ is modulus of elasticity of subsoil;

$t$ is foundation thickness;

$B, L$ are foundation width " $B$ ", length " $L$ ", respectively.

For assessment of square foundations stiffness it is valid $B=L$. For relative stiffness $k<1$, the foundation was considered flexible and for $k>1$, the foundation was considered rigid.

A steel foundation model was applied. This model was put on the dense sand subsoil. The subsoil below 
foundation was modeled as a cylinder with diameter $0.8 \mathrm{~m}$ and height $0.8 \mathrm{~m}$. The physical properties of foundations and subsoil are listed in Table 2 . Foundation model was loaded by axial forces of various values " $F_{i}$ " (axial forces $F_{1}$ to $F_{7}$ ) which affect the average contact stresses of values from $\sigma_{m 1}=3.2$ $\mathrm{kPa}$ to $\sigma_{m 7}=76.5 \mathrm{kPa}$, i.e., elastic zone of dense sand subsoil.

\section{Mathematical Procedures of Calculation Models}

Computer program ANSYS $^{\circledR}$ [27] was used for analysis of the problem. Interaction of foundation with subsoil was solved by deformation variant of FEM based on the Lagrange variational principle of the minimum total potential energy of the internal and external forces. Mathematical formulation of static analyses of the structure (assuming the bi-directional and one-directional bonds between foundation and subsoil) was presented in symbolic form [27]:

$$
[K] \cdot\{u\}=\{F\}
$$

where,

$[k]$ is the stiffness matrix of the system (model);

$\{u\}$ is displacement vector of nodal point;

$\{F\}$ is vector of surface and volume forces.

Geometrical nonlinearity of the analyzed problem was modeled by the boundary conditions of one-directional bond using FEM elements "TARGE 170" and "CONTA 174". In application of above mentioned contact elements the theory of large deflections was considered. The stress-strain relation of the problem was defined as follows [27]:

$$
\{\sigma\}=[D] \cdot\left\{\varepsilon^{e l}\right\}
$$

where,

$\{\sigma\}$ is stress vector;

$\{D\}$ is matrix of material constants;

$\left\{\varepsilon^{e l}\right\}$ is vector of elastic strains (the effects of temperature changes were neglected).

Next, the final system of linear equations by Jacobi's iterative method and system of nonlinear equations by Newton-Raphson's iterative method

\begin{tabular}{|c|c|c|c|c|c|}
\hline \multicolumn{2}{|c|}{ Foundation model marking } & \multirow{2}{*}{$\begin{array}{l}\text { Width (length) } \\
\text { of foundation } \\
B(\mathrm{~L})(\mathrm{mm})\end{array}$} & \multirow{2}{*}{$\begin{array}{l}\text { Thickness } \\
\text { of foundation } \\
t(\mathrm{~mm})\end{array}$} & \multirow{2}{*}{$\begin{array}{l}\text { Relative stiffness } \\
k(-)\end{array}$} & \multirow{2}{*}{$\begin{array}{l}\text { Assessment of } \\
\text { foundation stiffness }\end{array}$} \\
\hline Bi-directional & One-directional & & & & \\
\hline $\mathrm{Sq}(100)$ & $\mathrm{Sq}(100) \mathrm{c}$ & \multirow{6}{*}{$200.0(200.0)$} & 100.0 & $1,009.62$ & Rigid \\
\hline $\mathrm{Sq}(25)$ & $\mathrm{Sq}(25) \mathrm{c}$ & & 25.0 & 15.78 & Rigid \\
\hline $\mathrm{Sq}(15)$ & $\mathrm{Sq}(15) \mathrm{c}$ & & 15.0 & 3.41 & Rigid \\
\hline $\mathrm{Sq}(10)$ & $\mathrm{Sq}(10) \mathrm{c}$ & & 10.0 & 1.00 & Rigid-flexible \\
\hline $\mathrm{Sq}(5)$ & $\mathrm{Sq}(5) \mathrm{c}$ & & 5.0 & 0.12 & Flexible \\
\hline $\mathrm{Sq}(2.5)$ & $\mathrm{Sq}(2.5) \mathrm{c}$ & & 2.5 & 0.015 & Flexible \\
\hline $\mathrm{C}(100)$ & $\mathrm{C}(100) \mathrm{c}$ & \multirow{5}{*}{240.0} & 100.0 & 584.2 & Rigid \\
\hline $\mathrm{C}(25)$ & $\mathrm{C}(25) \mathrm{c}$ & & 25.0 & 9.13 & Rigid \\
\hline $\mathrm{C}(15)$ & $\mathrm{C}(15) \mathrm{c}$ & & 15.0 & 1.97 & Rigid \\
\hline $\mathrm{C}(10)$ & $\mathrm{C}(10) \mathrm{c}$ & & 10.0 & 0.58 & Flexible \\
\hline $\mathrm{C}(5)$ & $\mathrm{C}(5) \mathrm{c}$ & & 5.0 & 0.07 & Flexible \\
\hline St (100) & St $(100) c$ & \multirow{5}{*}{$65.0(630.0)$} & 100.0 & 32.300 & Rigid \\
\hline St (30) & $\mathrm{St}(30) \mathrm{c}$ & & 30.0 & 0.872 & Flexible \\
\hline St (15) & St (15)c & & 15.0 & 0.109 & Flexible \\
\hline St (10) & $\mathrm{St}(10) \mathrm{c}$ & & 10.0 & 0.032 & Flexible \\
\hline St (5) & $\mathrm{St}(5) \mathrm{c}$ & & 5.0 & 0.004 & Flexible \\
\hline
\end{tabular}

Table 1 Geometrical characteristics and stiffness of square, circular and strip foundations.

Table 2 Physical properties of shallow foundations and subsoil.

\begin{tabular}{lllll}
\hline \multirow{2}{*}{ Model } & \multirow{2}{*}{ Material } & \multicolumn{3}{c}{ Physical properties } \\
\cline { 3 - 5 } & & Modulus of elasticity E (MPa ) & Poisson's ratio v (-) & Relative density $\mathrm{I}_{\mathrm{D}}(-)$ \\
\hline Foundation & Steel & 210,000 & 0.20 & - \\
Subsoil & Sand (dense) & 26 & 0.28 & 0.7 \\
\hline
\end{tabular}


were solved. The convergence condition for iterative processes was defined by Ref. [27]:

$$
\|\{R\}\|<\varepsilon_{R} \cdot R_{\text {ref }}
$$

where,

$\{R\}=\left\{F^{a}\right\}-\left\{F^{n r}\right\}$ is vector of residual nodal forces, or disequilibrium of external and internal forces;

$R_{\text {ref }}=\left\|\left\{F^{a}\right\}\right\|$ is reference force equal to vector of external forces;

$\varepsilon_{R}$ is tolerance coefficient;

$\left\{F^{a}\right\}$ is vector of external forces;

$\left\{F^{n r}\right\}$ is vector of internal (nodal) forces.

In solution of force convergence criteria defined by tolerance coefficients, $\varepsilon_{R}=1 . \mathrm{e}^{-8}$ for the linear solution and $\varepsilon_{R}=1 . \mathrm{e}^{-3}$ for nonlinear calculations were defined, respectively. For meshing of continuous region of the subsoil model and foundation 3D finite elements "SOLID 45" were used. Similarly, for modeling of bi-directional bonding between foundation and subsoil the same type of elements was used. Eight-nodal 3-D contact elements (TARGE 170 + CONTA 174) were used for modeling of one-directional bond in the foundation-subsoil contact. Contact elements were defined by basic material properties, i.e., friction coefficient $(M U=\operatorname{tg} \varphi)$ between foundation and subsoil. The Coulomb theory [27] for modeling of friction between foundation and subsoil was considered. Numerical models of rigid square, circular and strip foundations $(t=100 \mathrm{~mm})$ with one-directional bond and static boundary conditions are given in Fig. 1. The symmetry factor of the problem was utilized in the calculation process. The element meetings of calculation of square foundations rigid models for bi-directional and one-directional bonds and static boundary conditions are given in Fig. 2.

\section{Contact Stresses-Evaluation of Numerical Results}

Numerical results obtained above represent a valuable source of qualitative and quantitative specifications of the analyzed problems. Quantitative comparison of results of contact stresses for different values of stiffness and bonds is given in Table 3. Qualitative interpretation of stiffness affecting the intensity of relative vertical normal $\left(\sigma_{z} / \sigma_{m}\right)$ and shear $\left(\tau_{y z} / \sigma_{m}\right)$ contact stresses for centre and corner of the shallow square, circular and strip foundations are shown in Figs. 3-5. From the calculation following values of effects of friction with one-directional bond (if $\varphi=35^{\circ}$ or $\varphi=0^{\circ}$ ) were obtained:

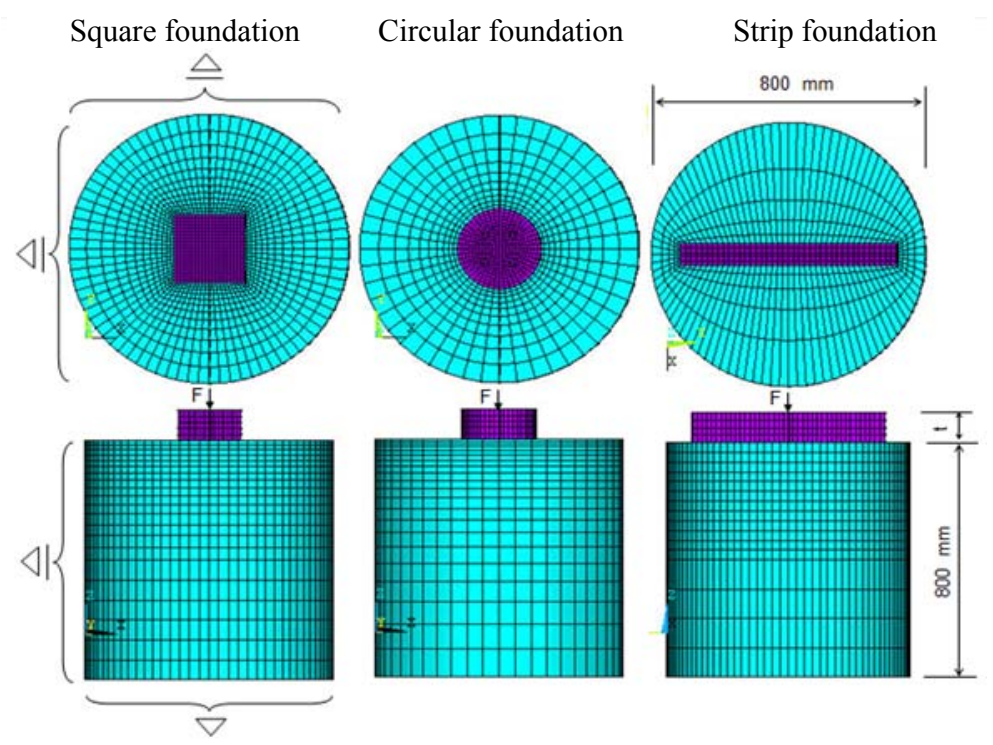

Fig. 1 Numerical models of rigid foundations $(t=100 \mathrm{~mm})$ with one-directional bond and static boundary conditions. 

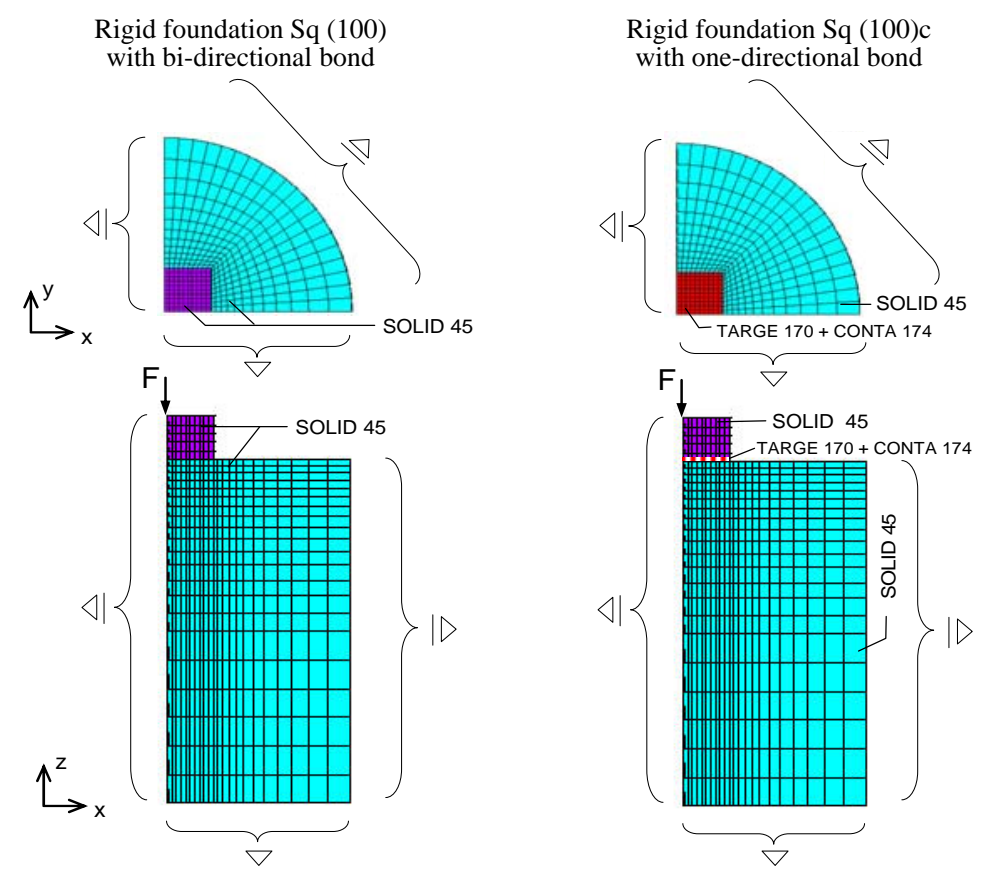

Fig. 2 Calculation model of rigid square foundations with bi-directional “Sq (100)" and one-directional "Sq (100)c" bonds.

Table 3 Quantitative comparison of relative vertical normal and shear contact stresses in representative point of rigid and flexible foundations on the contact surface.

\begin{tabular}{|c|c|c|c|c|c|c|c|c|c|}
\hline \multirow{4}{*}{$\begin{array}{l}\text { Geometrical } \\
\text { shape of } \\
\text { foundations }\end{array}$} & \multirow{4}{*}{$\begin{array}{l}\text { Point location } \\
\text { on contact } \\
\text { surface }\end{array}$} & \multicolumn{8}{|c|}{ Contact stresses calculated under average loading intensity $\sigma_{m}=50.0(\mathrm{kP})$} \\
\hline & & \multicolumn{4}{|c|}{ Bi-directional bond (with solid contact) } & \multicolumn{4}{|c|}{ One-directional bond (with friction if $\varphi=35^{\circ}$ ) } \\
\hline & & \multicolumn{2}{|c|}{$\begin{array}{l}\text { Relative normal stress } \\
\sigma_{z} / \sigma_{m}(-)\end{array}$} & \multicolumn{2}{|c|}{$\begin{array}{l}\text { Relative shear stress } \\
\tau_{y z} / \sigma_{m}(-)\end{array}$} & \multicolumn{2}{|c|}{$\begin{array}{l}\text { Relative normal stress } \\
\sigma_{z} / \sigma_{m}(-)\end{array}$} & \multicolumn{2}{|c|}{$\begin{array}{l}\text { Relative shear stress } \\
\tau_{y z} / \sigma_{m}(-)\end{array}$} \\
\hline & & $R(k>1)$ & $F(k=0.1)$ & $R(k>1)$ & $F(k=0.1)$ & $R(k>1)$ & $F(k=0.1)$ & $R(k>1)$ & $F(k=0.1)$ \\
\hline \multirow{3}{*}{ Square } & Centre & -0.489 & -3.788 & 0 & 0 & -0.502 & -3.785 & 0 & 0 \\
\hline & Boundary & -1.480 & -0.553 & 0.338 & 0.390 & -1.399 & -0.630 & 0.283 & 0.250 \\
\hline & Corner & -3.095 & -0.515 & 0.569 & 0.103 & -2.500 & -0.022 & 0.437 & 0.032 \\
\hline \multirow{2}{*}{ Circular } & Centre & -0.507 & -2.815 & 0 & 0 & -0.518 & -2.778 & 0 & 0 \\
\hline & Boundary & -1.876 & -0.372 & 0.404 & 0.342 & -1.801 & -0.413 & 0.332 & 0.229 \\
\hline \multirow{3}{*}{ Strip } & Centre & -0.507 & -1.244 & 0 & 0 & -0.550 & -1.361 & 0 & 0 \\
\hline & Corner & -1.438 & 0.538 & 0.267 & 0.030 & -1.048 & -0.003 & 0.172 & 0.007 \\
\hline & Boundary (L) & -1.035 & 0.449 & 0.226 & 0.016 & -0.989 & -0.003 & 0.225 & 0.007 \\
\hline
\end{tabular}

Remark: $R$-rigid foundation $(k>1$, or $k=30) ; F$-flexible foundation $(k=0.1)$.

(1) in the case of vertical normal contact stress less than $10 \%$ (maximal);

(2) in the case of shear stresses less than $15 \%$ (maximal).

In Figs. 3-5, the relative contact stresses for bi-directional and one-directional bonds with friction (if $\varphi=35^{\circ}$ ) are shown. Graphical representation of vertical normal and shear stresses calculated for flexible and rigid square foundation are shown in Figs. 6 and 7. Relative contact stresses were evaluated under action of average normal stress $\sigma_{m}=50 \mathrm{kPa}$.

The calculation results have proved that geometric shape and foundation structures stiffness substantially affect the value and distribution of contact stresses in the foundation subsoil. On the other hand, effects of bonds and friction on the contact surface affect the value and distribution of contact stresses only to smaller extent. 


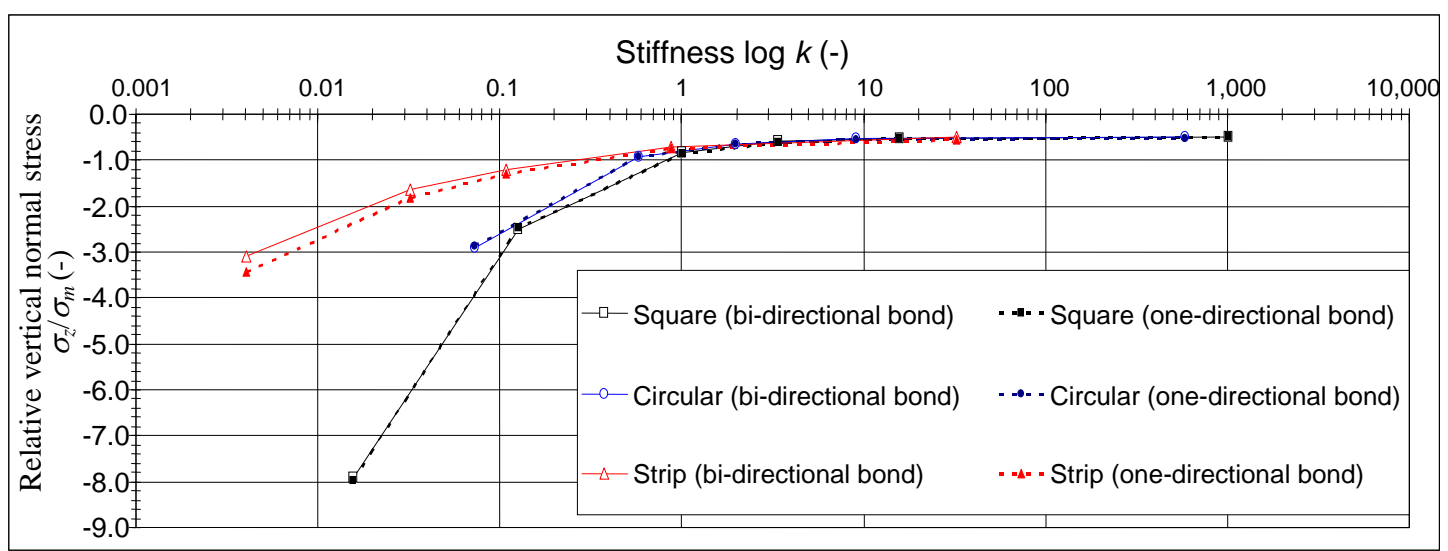

Fig. 3 Effects of rigidity and bonding on the normal stress below the centre of foundation.

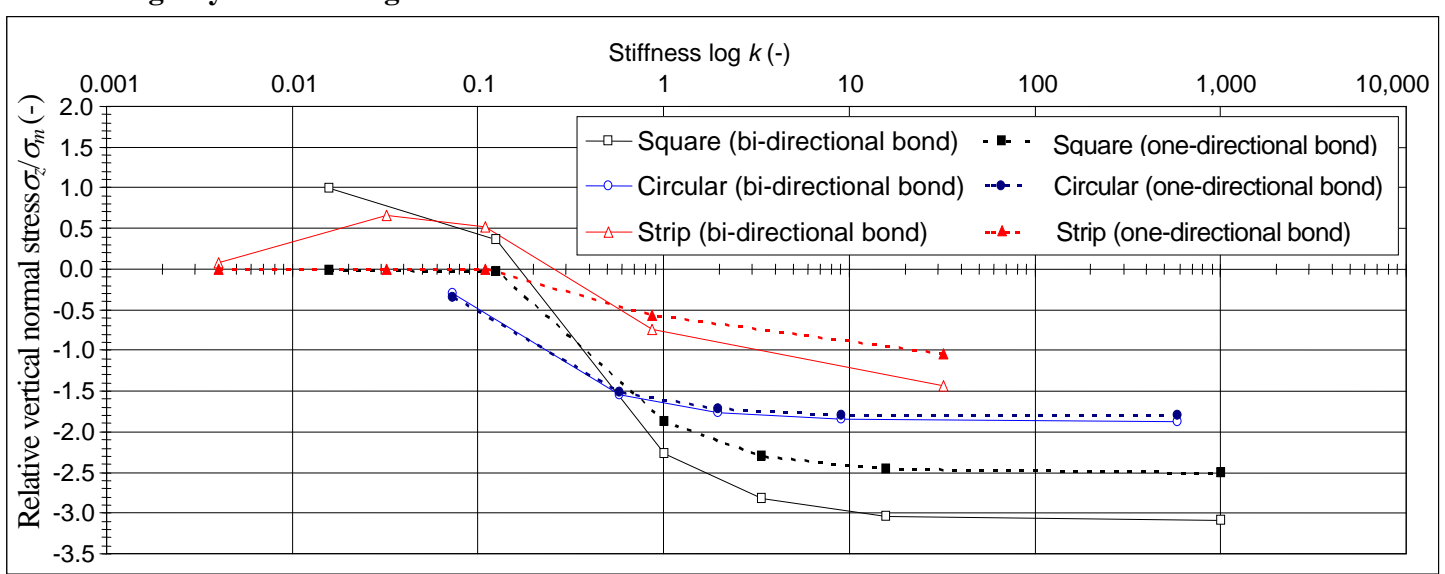

Fig. 4 Effects of rigidity and bonding on the normal stress below the corner of foundation.

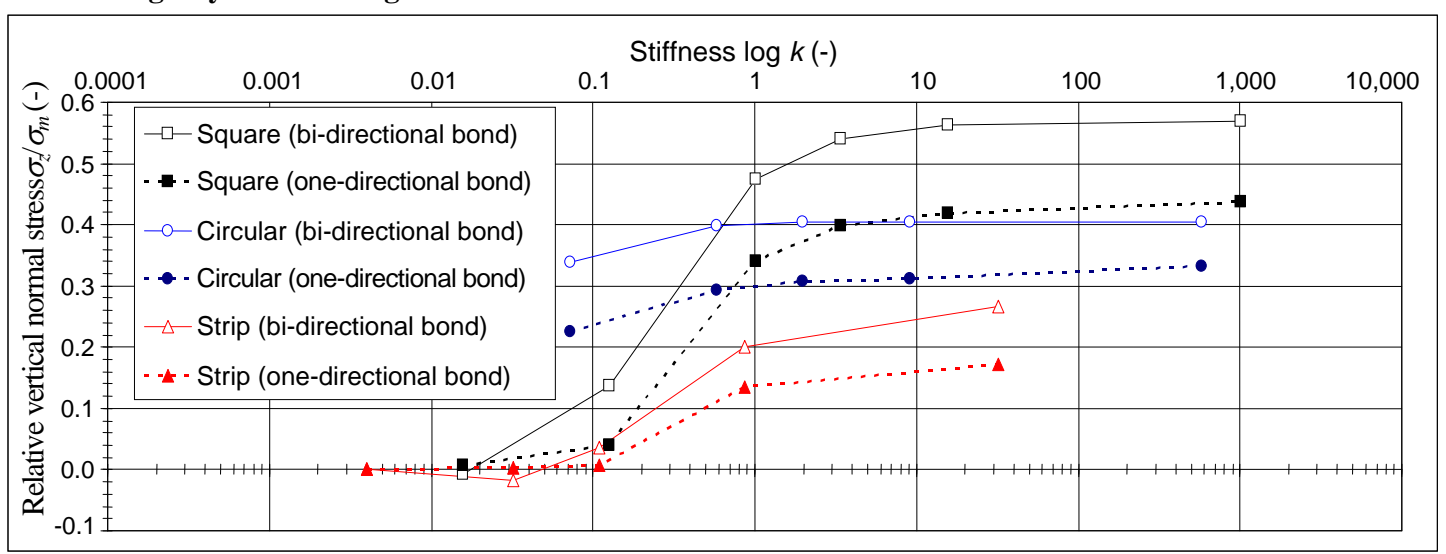

Fig. 5 Effects of rigidity and bonding on the shear stress below the corner of foundation.

\section{Deformations, Relative Deformations and Deflections of the Shallow} Foundations-Evaluation of Numerical Results

The numerical analyses of rigid and flexible shallow (square, circular and strip) foundations represent a valuable source of qualitative and quantitative specifications of the effects of stiffness, bonds (bi-directional and one-directional) and friction on the vertical deformations (settlements), deflections and relative deformations (relative settlement, relative deflection and flexibility). Deformations of square, circular and strip foundations were evaluated for 


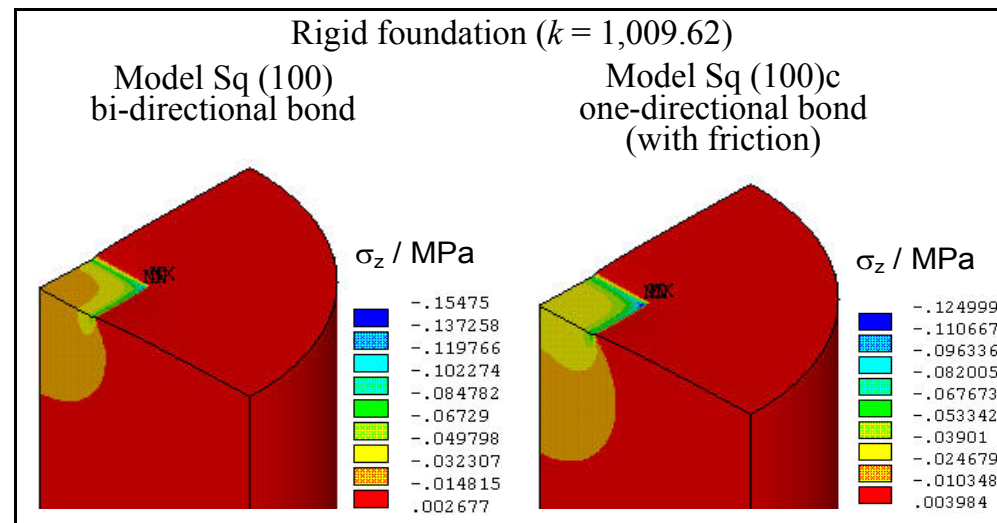

Flexible foundation $(k=0.01)$

Model Sq (2.5)

bi-directional bond

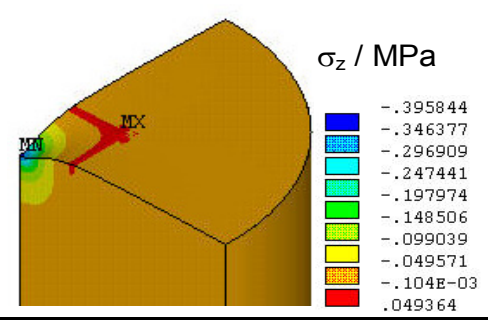

Model Sq (2.5)c one-directional bond (with friction)

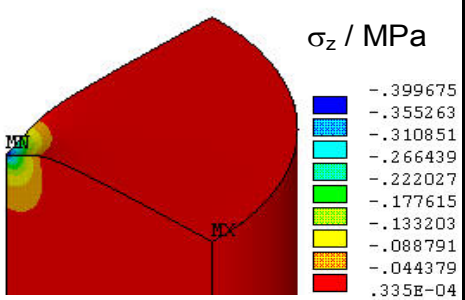

Fig. 6 Graphical representation of vertical normal contact stresses calculated for flexible and rigid square foundations (intensity of average loading $\sigma_{m}=50 \mathrm{kPa}$ ).

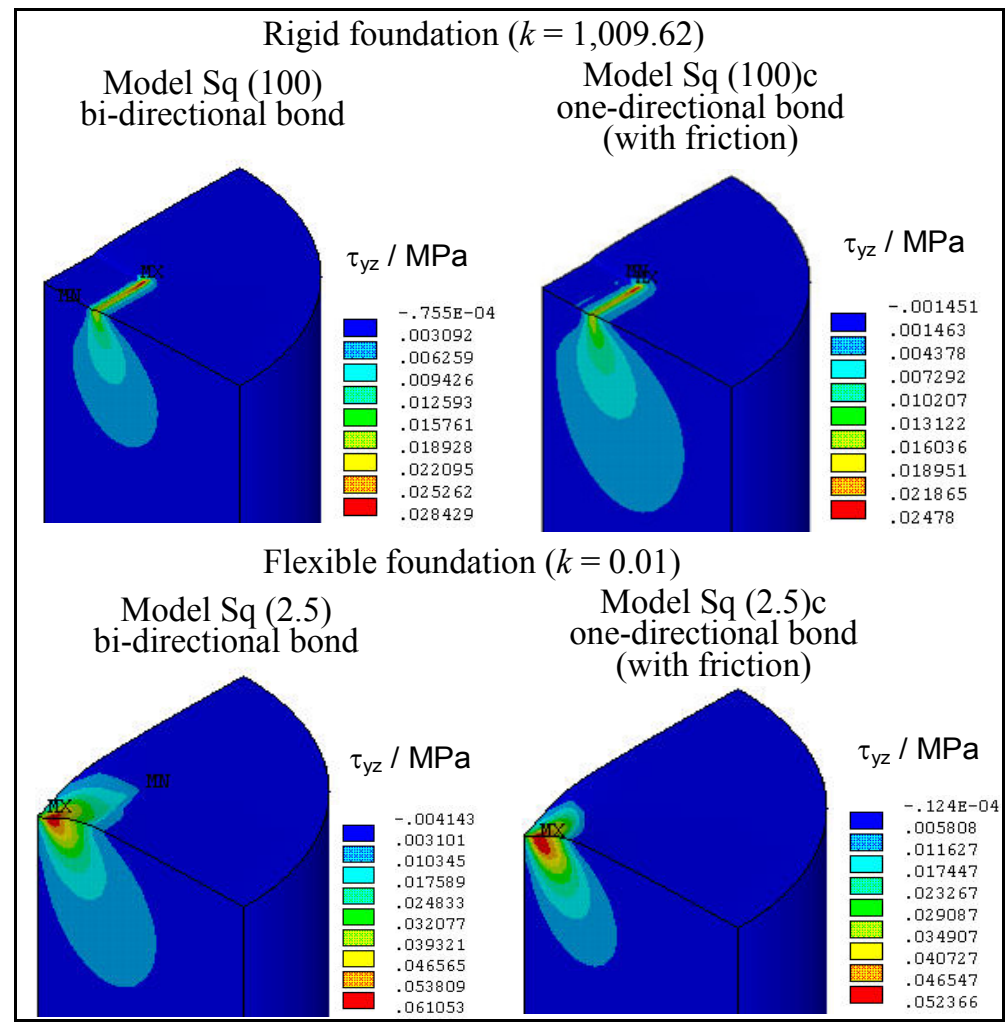

Fig. 7 Graphical representation of shear contact stresses calculated for flexible and rigid square foundations (intensity of average loading $\sigma_{m}=50 \mathrm{kPa}$ ). 
boundary points of shallow foundations (Fig. 8).

From the calculated vertical displacements (settlements) of foundation models calculated by FEM in representative points (Fig. 8) following relative characteristics were evaluated:

(1) deflection calculated by formula:

$$
\Delta s=s_{\text {max }}-s_{\text {min }}
$$

(2) relative settlement calculated by formulas:

$$
\text { for axis: } \begin{array}{r}
\frac{s_{a}}{s_{\max }} \text {; for corner } \frac{s_{r}}{s_{\max }} \text {; } \\
\text { for boundary: } \frac{s_{b}}{s_{\max }}
\end{array}
$$

(3) relative deflection calculated by formula:

$$
\frac{\Delta s}{B}
$$

(4) flexibility calculated by formula:

$$
\frac{\Delta s}{s_{\max }}
$$

Graphical interpretation of the stiffness, bonds (bi-directional, one-directional) and friction effects on the value of deflection, relative settlement, relative deflection and flexibility are presented in Figs. 9-12. Graphical representation of vertical displacements (settlements) calculated for rigid "Sq (100)" and flexible "Sq (2.5)" square foundation (with one-directional and bi-directional bonds) for average contact stress $\sigma_{m}=50 \mathrm{kPa}$ are shown in Fig. 13. From the presented results, it is obvious that effects of stiffness on deformations (deflection, relative settlement, relative deflection and flexibility) of foundations are very significant (non-negligible in practical calculations).

On the other hand, effect of bonds (bi-directional, one-directional) is relatively small up to value of stiffness $k \geq 0.1$ (negligible in practical calculations). Effects of friction (with one-directional bond) are relatively weak for all stiffness's of foundations. Foundations can be considered perfectly rigid if the relative stiffness $k>10$.

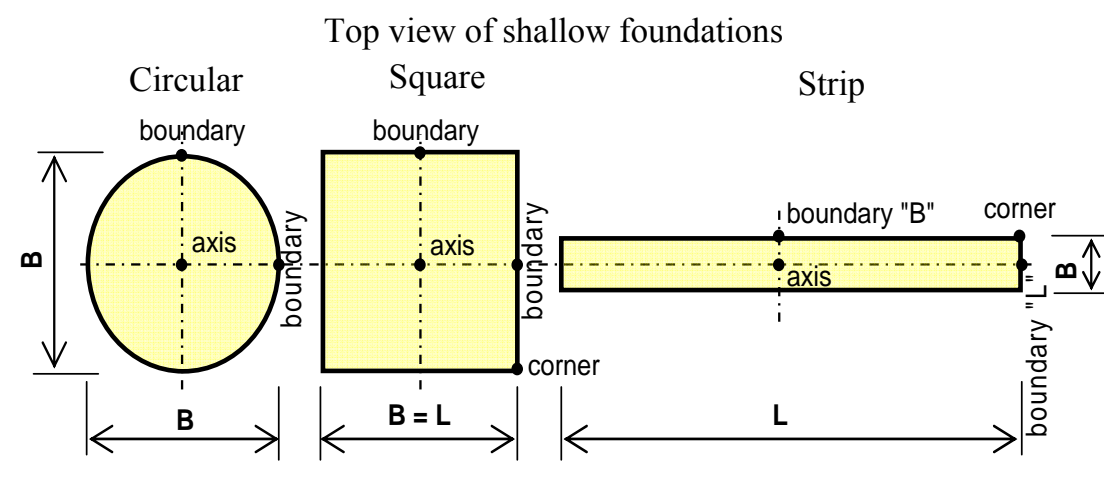

Section

Flexible foundation Rigid foundation
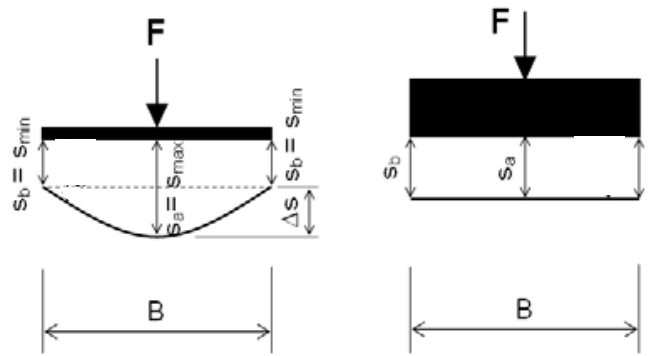

Fig. 8 Position of representative points on shallow (circular, square and strip) foundations and designation of vertical displacement (settlement) calculated for rigid and flexible foundation. 


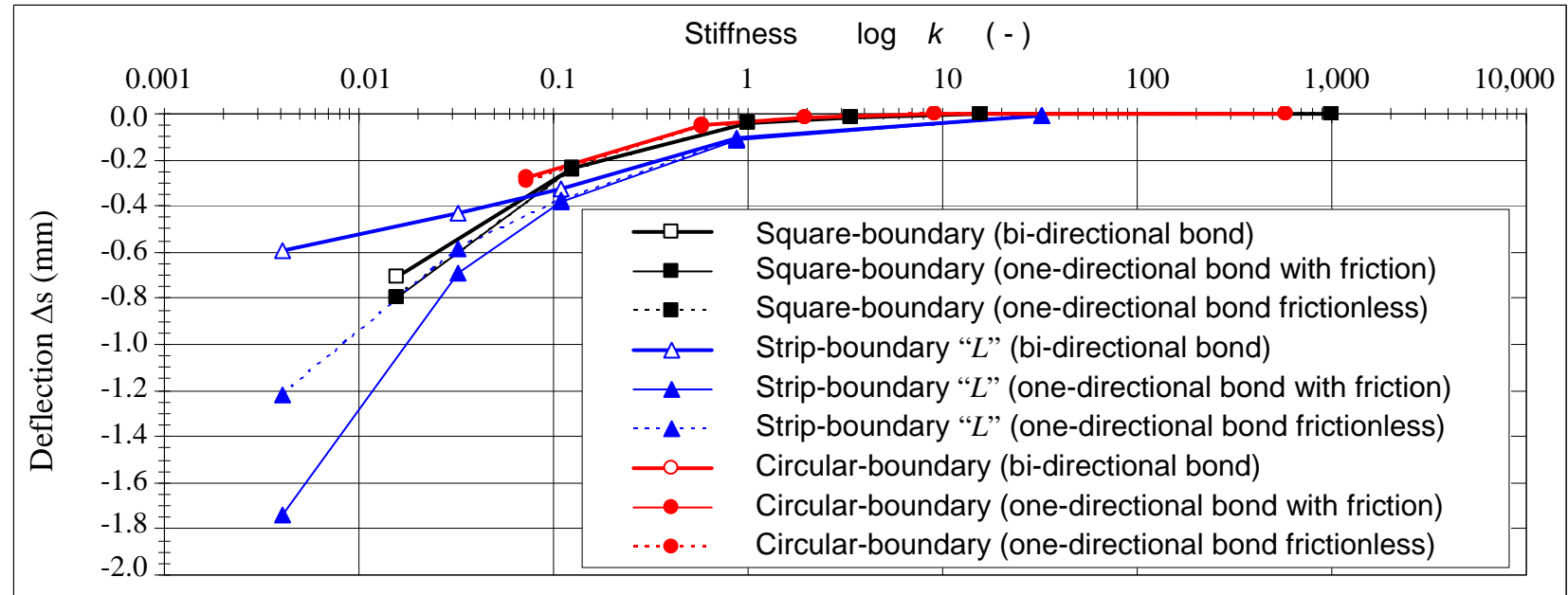

Fig. 9 Effects of stiffness, bonds and friction on the deflection in boundary of square, circular and strip foundations.

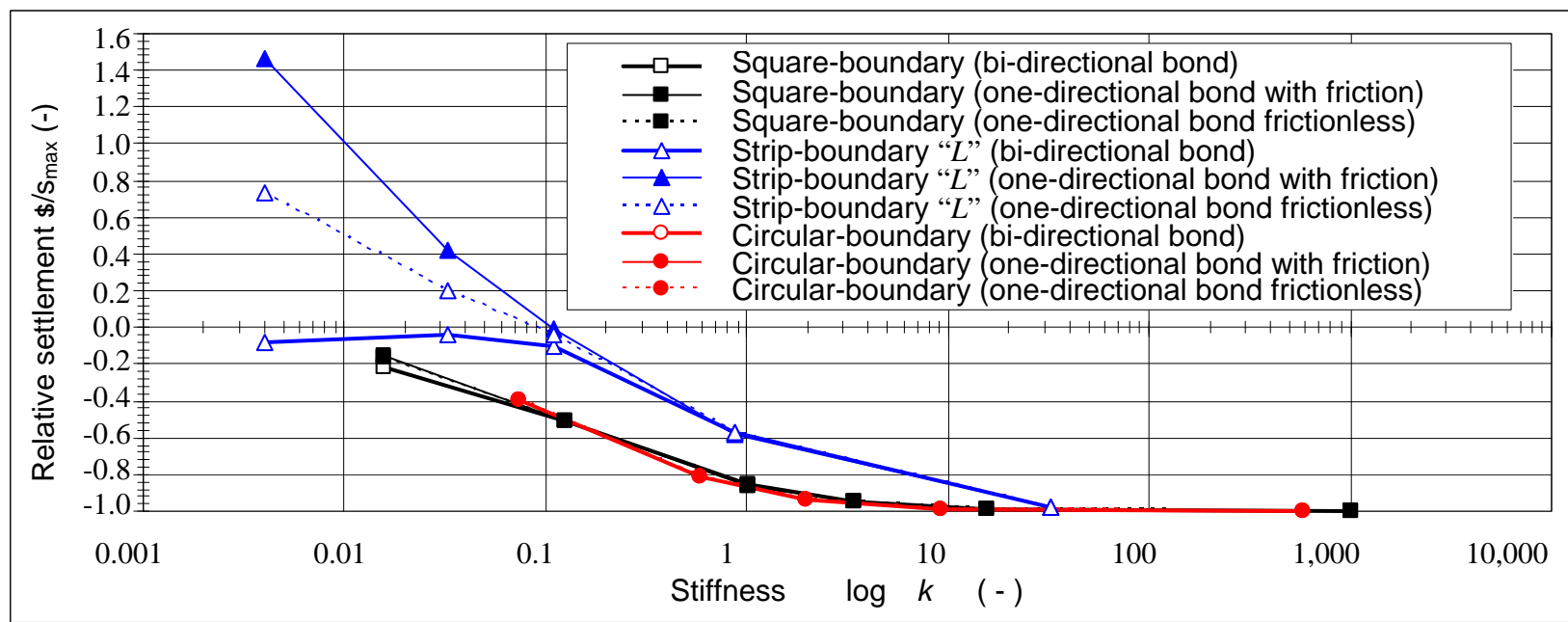

Fig. 10 Effects of stiffness, bonds and friction on the relative settlement in boundary of square, circular and strip foundations.

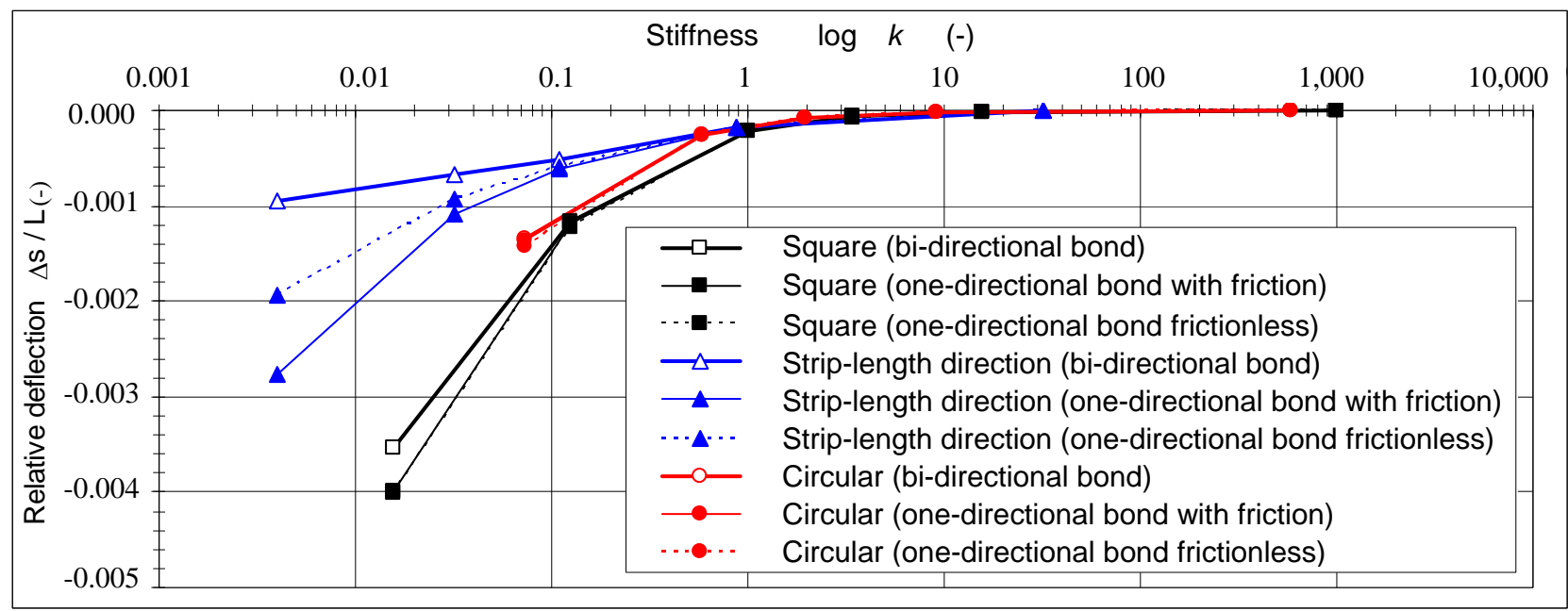

Fig. 11 Effects of stiffness, bonds and friction on the relative deflection in boundary of square, circular and strip foundations. 


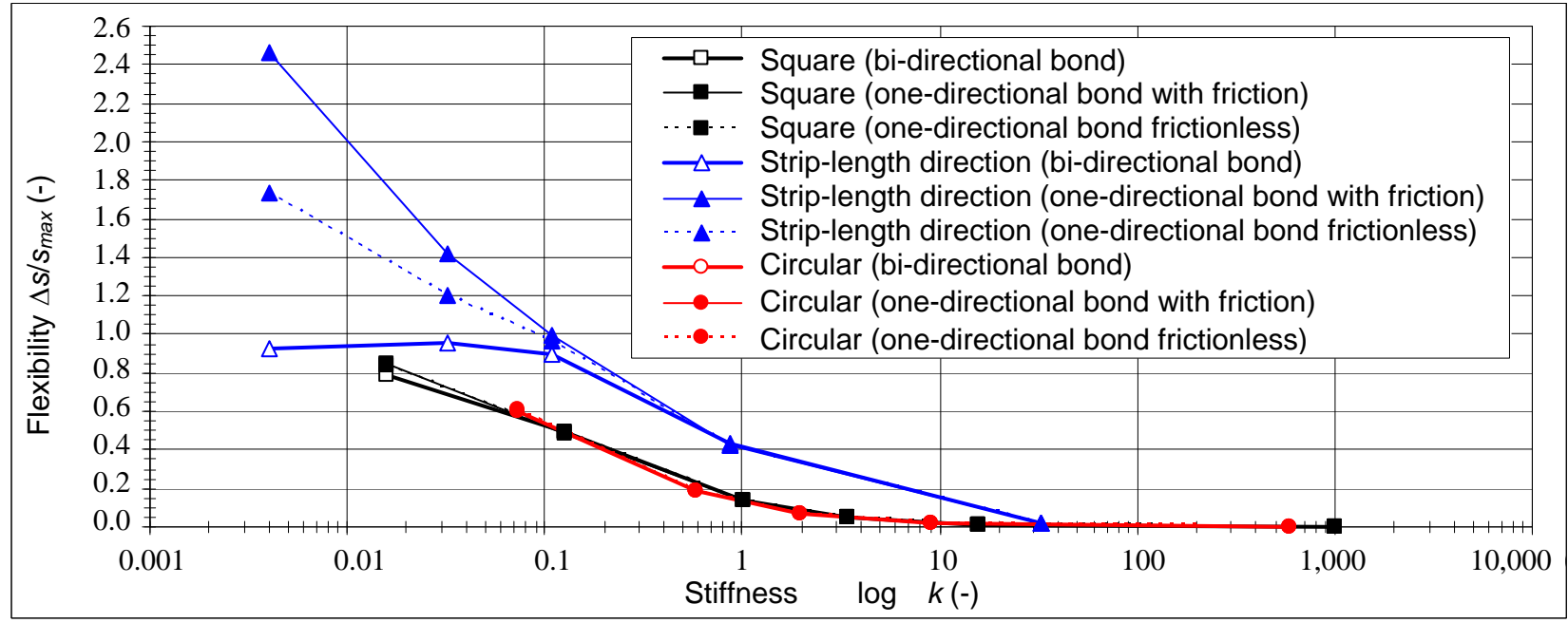

Fig. 12 Effects of stiffness, bonds and friction on the flexibility in boundary of square, circular and strip foundations.

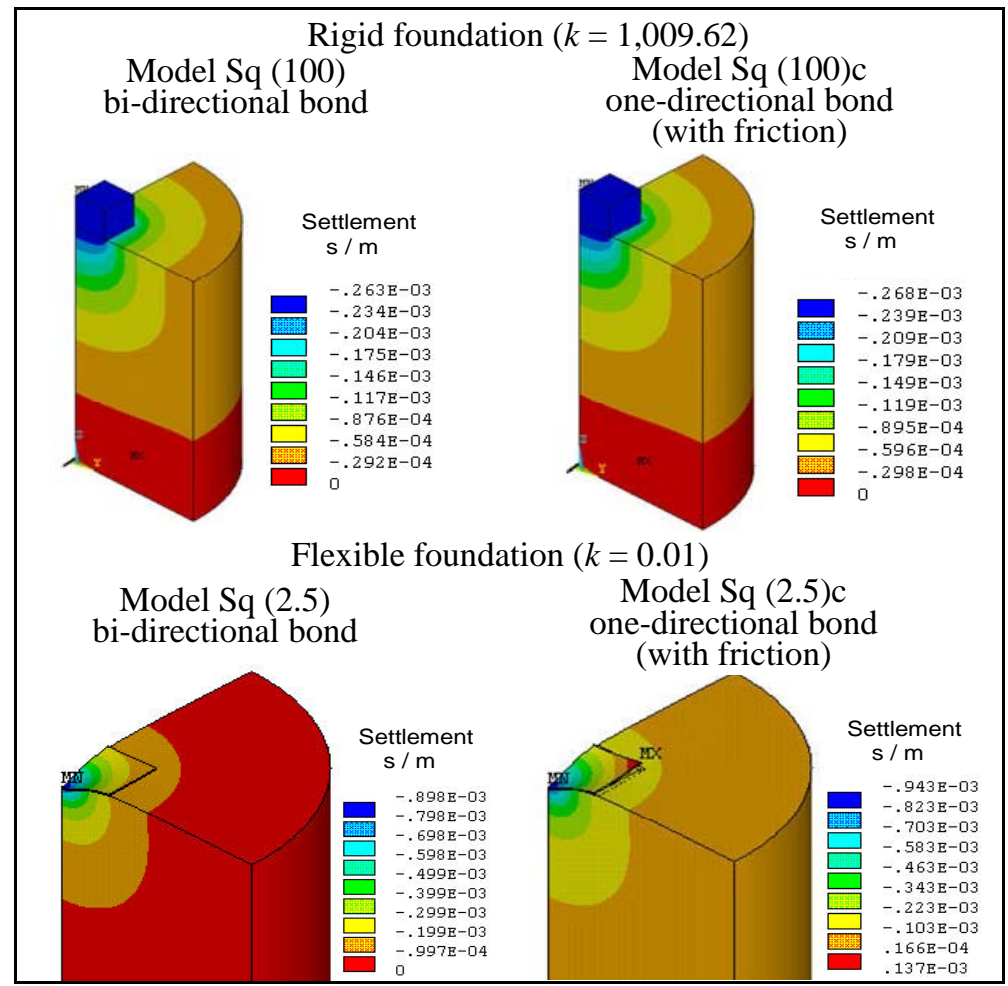

Fig. 13 Graphical representation of settlements calculated for rigid "Sq (100)" and flexible "Sq (2.5)" square foundation (with one-directional and bi-directional bonds) for average contact stress $\sigma_{m}=50 \mathrm{kPa}$.

\section{Conclusions}

The use of numerical methods (FEM modeling) and mathematical tools allows solving of practical engineering problems in a more realistic way, taking into account the effects of stiffness, friction on the contact area between square, circular and strip foundations and subsoil. The application of FEM modeling enables us to determine correctly the value of the contact stresses (vertical normal and shear stresses), vertical deformation (settlement), deflection and relative deformation (relative settlement, relative deflection and flexibility) of rigid and flexible shallow (square, circular and strip) foundations. Presented calculations show that considering the effects of stiffness, bonds and friction in the foundation bottom 
allows more realistic and economical design of shallow foundations, meeting the criteria of the required reliability.

From the presented calculation results it is obvious that relative stiffness of the system "foundation structure-subsoil” substantially affects distribution of contact stresses in the foundation subsoil and displacements (settlement, deflection and relative deformations, flexibility) of foundation. In the case of flexible foundations, the bond on the contact surfaces must be considered during the calculation. On the other hand, the effects of friction on the contact surface between the foundation and subsoil affect the distribution of contact stresses and deformations only to smaller extent.

\section{References}

[1] L. Bolteus, Soil-structure interaction, developments in geotechnical engineering, Elsevier 43 (1984) 377-378.

[2] G.G. Meyerhof, Soil-structure interaction and foundations, in: Proceedings of the 6th Panam, CSMFE—General Report-Main Session III, Lima, 1979, pp. 109-140.

[3] K. Biernatowski, W. Pytel, Design model of soil-structure interaction including reliability theory, in: Proceedings of the 10th International Conference on Soil Mechanics and Foundation Engineering, Balkema, Stockholm, 1981, pp. 45-48.

[4] H.G. Poulos, Soil-structure interaction, in: Proceedings of the 10th International Conference on Soil Mechanics and Foundation Engineering, Balkema, Stockholm, 1981, pp. 307-309.

[5] A. Hashemi, T. Elkhoraibi, F. Ostadan, Probabilistic and deterministic soil structure interaction (SSI) analysis, in: Proceeding of the 11th International Conference on Applications of Statistics and Probability in Civil Engineering, Taylor \& Francis, 2011, pp. 907-915.

[6] W.D.L. Finn, Aspects of soil structure interaction, in: The International Workshop on Soil-Foundation-Structure Interaction, Taylor \& Francis, Balkema, 2010, pp. 69-75.

[7] M. Moghaddasi, M. Cubrinovski, J.G. Chase, S. Pampanin, A. Carr, Stochastic quantification of soil-shallow foundation-structure interaction, Journal of Earthquake Engineering 16 (6) (2012) 820-850.

[8] B. Zhu, D.Q. Kong, L.G. Kong, R.P. Chen, Y.M. Chen, Study on soil-structure interaction of suction caisson by large-scale model tests, in: Proceeding of the 2nd International Symposium on Frontiers in Offshore
Geotechnics-Frontiers in Offshore Geotechnics II, Balkema, 2011, pp. 647-652.

[9] F. Kopf, A. Bekö, D. Schäfer, M. Pietsch, L. Rossbacher, The assessment of soil-structure-interaction by measurements, in: Proceedings of the 3rd International Symposium on Life-Cycle Civil Engineering (IALCCE'12), CRC Press, Vienna, 2012, pp. 1485-1492.

[10] O.C. Zienkiewicz, R.L. Taylor, The Finite Element Method, Basic Formulations and Linear Problems, 4th ed., McGRAW-HILL, London, 1991, p. 654.

[11] O.C. Zienkiewicz, R.L. Taylor, The Finite Element Method, Solid and Fluid Mechanics, 4th ed., McGRAW-HILL, London, 1991, p. 807.

[12] L.F. Boswell, The application of the finite element method to some soil structure interaction problems, in: Proceedings of the International Symposium on Numerical Methods in Soil Mechanics and Rock Mechanics, Karlsruhe, 1976, pp. 125-134.

[13] C.S. Desai, Soil structure interaction and simulation problems, in: Proceedings of the International Symposium on Numerical Methods in Soil Mechanics and Rock Mechanics, Karlsruhe, 1976, pp. 121-123.

[14] H. Langen, Numerical Analysis of Soil-Structure Interaction, Delft, University of Technology, 1991, p. 141.

[15] X. Zhang, P. Gotteland, P. Foray, S. Lambert, A. Hatem, Numerical Modeling of Inertial Soil-Inclusion Interaction, Numerical Methods in Geotechnical Engineering (NUMGE 2010), CRC Press, 2010, pp. 869-874.

[16] W.D.L. Finn, H.B. Pandey, C.E. Ventura, Modeling Soil-Foundation-Structure Interaction, Structural Design of Tall and Special Buildings, John Wiley \& Sons, 2011, pp. 47-62.

[17] C. Mozos, J. Luco, Approximate boundaries for finite-element models of static soil-foundation interaction problems, Journal of Engineering Mechanics 137 (10) (2011) 648-659.

[18] S.K. Bose, S.C. Das, Non-linear finite element analysis of stresses and deformations beneath rigid footings, Computer and Structures 62 (3) (1997) 487-492.

[19] U. Bergdahl, G. Hult, E. Ottosson, Calculation of settlements of footings in sand, in: Proceedings of the 11th Conference on Soil Mechanics and Foundation Engineering, San Francisco, 1985, pp. 2167-2170.

[20] H. Denver, Settlement calculation for footings on sand, in: Proceedings of the 11th Conference on Soil Mechanics and Foundation Engineering, San Francisco, 1985, pp. 2183-2190.

[21] G.A. Leonards, J.D. Frost, Settlement of shallow foundations on granular soils, Journal of Geotechnical Engineering 114 (7) (1988) 791-809.

[22] L. Montrasio, R. Nova, Settlements of shallow 
foundations on sand-geometrical effects, Geotechnique 47 (1) (1997) 49-60.

[23] E. Schultze, Distribution of stresses beneath a rigid foundation, in: Proceedings of the 5th International Conference on Soil Mechanics and Foundation Engineering, Paris, 1961, p. 807.

[24] L.F. Boswell, C.R. Scott, A flexible circular plate on a heterogeneous elastic half-space, influence coefficients for contact stress and settlement, Geotechnique 25 (3) (1972) 604-610.

[25] J. Santos, J. Quera, Soil foundation interaction with friction at the interface, in: Proceedings of the 10th International Conference on Soil Mechanics and Foundation Engineering, Stockholm, 1981, pp. 253-258.

[26] L. Hruštinec, Interaction analysis of the shallow foundations with subsoil, Ph.D. Thesis, Slovak University of Technology in Bratislava, 2002, p. 689. (in Slovak)

[27] ANSYS ${ }^{\circledR}$, User’s Manuals, Swanson Analysis System, Vol. 1-4, 1999.

[28] STN 73 1001, Foundation of Structures - Subsoil under Shallow Foundation, Slovak Standard, 1987. (in Slovak) 